\title{
SCALOPS LATIMANUS.-BAсн.
}

\author{
Texan Shrew Mole.
}

SYNONYME.

Scalops Latimanus.-Bach, Boston Jour. Nat. History, vol, i., p. 41.

DESCRIPTION.

Larger than the common shrew-mole, intermediate in size between $\boldsymbol{S}$. Townsendi and S. Breweri. Hair longer and thinner than in either of the other species, and slightly curled. Palms larger than in any other known species. Tail naked.

COLOUR.

Colour nearly black.

DIMENSIONS.

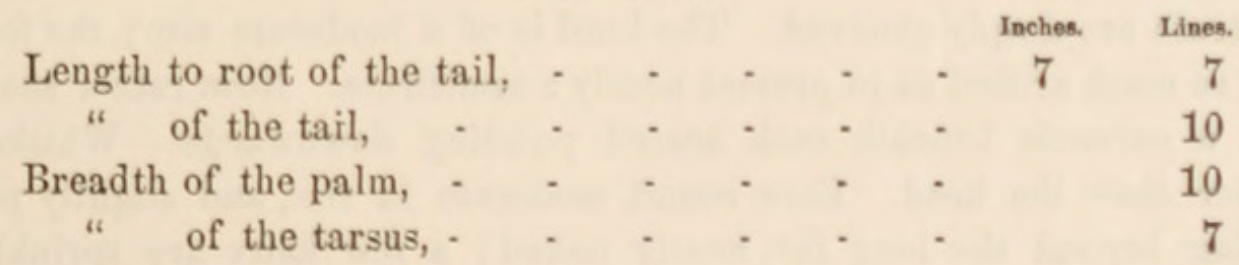

GEOGRAPHICAL DISTRIBUTION.

Mexico and Texas. 


\section{$2 \mathrm{BHL}$ Biodiversity Heritage Library}

Audubon, John James and Bachman, John. 1854. "Scalops latimanus, Texan Shrew Mole." The quadrupeds of North America 3, 323-323.

https://doi.org/10.5962/p.322536.

View This Item Online: https://www.biodiversitylibrary.org/item/108515

DOI: https://doi.org/10.5962/p.322536

Permalink: https://www.biodiversitylibrary.org/partpdf/322536

\section{Holding Institution}

Duke University Libraries (archive.org)

\section{Sponsored by}

Duke University Libraries

\section{Copyright \& Reuse}

Copyright Status: Not provided. Contact Holding Institution to verify copyright status.

This document was created from content at the Biodiversity Heritage Library, the world's largest open access digital library for biodiversity literature and archives. Visit BHL at https://www.biodiversitylibrary.org. 